\title{
Effect of Different Carbon Sources on Bacterial Nanocellulose Production and Structure Using the Low pH Resistant Strain Komagataeibacter Medellinensis
}

\author{
Carlos Molina-Ramírez ${ }^{1, *}$, Margarita Castro ${ }^{1}$, Marlon Osorio ${ }^{1}$, Mabel Torres-Taborda ${ }^{1}$, \\ Beatriz Gómez ${ }^{1}$, Robin Zuluaga ${ }^{2}$, Catalina Gómez ${ }^{1}$, Piedad Gañán ${ }^{1}$, Orlando J. Rojas ${ }^{3}$ \\ and Cristina Castro 4 \\ 1 Facultad de Ingeniería Química, Universidad Pontificia Bolivariana, Circular 1 , No. 70-01, Medellín 050031, \\ Colombia; margarita.castro@upb.edu.co (M.C.); marlonandres.osorio@upb.edu.co (M.O.); \\ mabel.torres@upb.edu.co (M.T.-T.); Beatriz.gomez@upb.edu.co (B.G.); catalina.gomezh@upb.edu.co (C.G.); \\ piedad.ganan@upb.edu.co (P.G.) \\ 2 Facultad de Ingeniería Agroindustrial, Universidad Pontificia Bolivariana, Circular $1^{\circ}$, No. 70-01, \\ Medellín 050031, Colombia; robin.zuluaga@upb.edu.co \\ 3 Biobased Colloids and Materials Group (BiCMat), Department of Bioproducts and Biosystems, \\ School of Chemical Engineering, Aalto University, Espoo 02150, Finland; orlando.rojas@aalto.fi \\ 4 Facultad de Ingeniería Textil, Universidad Pontificia Bolivariana, Circular 1ㅜ, No. 70-01, Medellín 050031, \\ Colombia; cristina.castro@upb.edu.co \\ * Correspondence: carlosan.molina@upb.edu.co
}

Received: 9 May 2017; Accepted: 7 June 2017; Published: 11 June 2017

\begin{abstract}
Bacterial cellulose (BC) is a polymer obtained by fermentation with microorganism of different genera. Recently, new producer species have been discovered, which require identification of the most important variables affecting cellulose production. In this work, the influence of different carbon sources in BC production by a novel low $\mathrm{pH}$-resistant strain Komagataeibacter medellinensis was established. The Hestrin-Schramm culture medium was used as a reference and was compared to other media comprising glucose, fructose, and sucrose, used as carbon sources at three concentrations $(1,2$, and $3 \% w / v)$. The BC yield and dynamics of carbon consumption were determined at given fermentation times during cellulose production. While the carbon source did not influence the BC structural characteristics, different production levels were determined: glucose $>$ sucrose $>$ fructose. These results highlight considerations to improve $B C$ industrial production and to establish the $B C$ property space for applications in different fields.
\end{abstract}

Keywords: bacterial nanocellulose; carbon source; cellulose crystallization; Komagataeibacter medellinensis; static fermentation

\section{Introduction}

Cellulose is the most abundant biopolymer on Earth, which is produced ( $10^{11}$ tons per year) by plants, alga, fungi, and bacteria [1]. Cellulose of plant origin is the most available and used: it is typically extracted by chemical and mechanical treatments from the natural cell wall matrix (comprising by cellulose, lignin, hemicellulose, and waxes) [2]. These treatments produce fibers with high size dispersion and may load the environment with residual components, if not utilized [3].

Gram-negative bacteria in Komagataeibacter (former Gluconacetobacter and Acetobacter) genus are mainly cellulose producer [4]; these bacteria are strictly aerobic and generate bacterial cellulose (BC) as an extracellular product at the air-medium interface at $\mathrm{pH}$ between 3 and 7 and temperatures between 28 and $30{ }^{\circ} \mathrm{C}$ [5-7]. Currently, some bacteria belonging to the Komagataeibacter genus have been reported to possess different metabolic preferences and to produce cellulose with different 
structural characteristics [8]. In fact, differences in the BC structural characteristics can be observed for those produced by different microorganisms using the same carbon source; for example, BC produced by Acetobacter sp.V6 [9] in glycerol has higher crystallinity than that produced in glucose. This is in contrast to Acetobacter xilinum which produce BC with lower crystallinity in glycerol [10].

In the specific case of K. medellinensis, it is important to highlight the advantage that the low $\mathrm{pH}$ required for $B C$ production reduces the risk for contamination by other microorganisms [11] and, therefore, $\mathrm{BC}$ production is not inhibited, as is otherwise the case for other bacteria of the same Komagataeibacter genus [12,13]. Additionally, in low $\mathrm{pH}$ conditions K. medellinensis produces cellulose that offers alternatives to modify it by alteration on culture media, this kind of in situ modifications of cellulose materials have a promising industrial application to paints, coatings, composite materials, or even biomedical devices [14,15].

The most studied species for cellulose production is Komagataeibacter xylinus (former Gluconacetobacter xylinus [16]. However, novel cellulose producer strains have been considered, such as K. medellinensis, which is Gram-negative bacilli, with $1-3 \mu \mathrm{m}$ in length and 0.6 to $0.7 \mu \mathrm{m}$ in width and are presented individually, in pairs or chains; also they are negative oxidase and positive catalase [17]. The colonies formed by this organism are beige, round, rough, and opaque.

The culture media commonly used for BC production require mainly a carbon and nitrogen source and salts to buffer the $\mathrm{pH}$ [18-20]. However, the optimum conditions for cellulose production with this microorganism have not been established yet. In fact, It is well known that there may be differences in metabolic preferences for microorganisms in the same genus between different species [21]. For example, K. xylinus have been tested for cellulose production on different carbon sources and the best results were determined when sucrose, glucose, fructose, or mannitol were used; fructose was reported to produce a small yield while glucose was considered the main carbon source for $\mathrm{BC}$ production compared to the other three sugars [8]. Compared to fermentation with glucose, fructose has been reported to produce low yields for the first four days while the highest production occurred on the fifth day [10,18-20,22-26]. This is because sucrose is a disaccharide composed of two hexoses (glucose and fructose) that must be hydrolyzed before its use in cellulose synthesis.

Fermentation process for cellulose production can be made under static or stirred conditions $[27,28]$. The static method is the most used to obtain BC in the laboratory, where the polymer grows into pellicles or films; meanwhile the agitated method is the most studied at industrial and biotechnological levels because it produces a higher level of oxygen transfer, which favors the production of cellulose. However, the agitated medium can induce cellular mutability such that a loss of $\mathrm{BC}$ productive capacity an occur and the BC produced may have low mechanical strength, crystallinity, and degree of polymerization $[22,27,29-31]$.

In this work, we inquired into the effect of carbon source on BC production yield and cellulose structure by using the novel acid-resistant strain K. medellinensis, as well as the dynamic of growth. The results will facilitate future work on how to improve $B C$ production and the methods to tailor $B C$ properties for different applications.

\section{Results}

\subsection{Effect of Carbon Source on Bacterial Cellulose Production}

The effect of carbon source concentration $(1,2,3 \% w / v)$ on bacterial cellulose production using the native strain K. medellinensis was evaluated (Figure 1). The highest BC yield on the basis of dry weight of the membranes per volume of medium was obtained at $2 \% w / v$ carbon source concentration, for all sources. The BC yield was $2.80,0.38$, and $1.68 \mathrm{~g} / \mathrm{L}$ using a $2 \% w / v$ of glucose, fructose, and sucrose, respectively. Compared with the dry weight of the membranes obtained from fructose and sucrose, a clear difference was observed for $\mathrm{BC}$ production from glucose. The results are in agreement with the observations of Castro et al. [32], Embuscado et al. [33], and others who have indicated that BC 
production is affected by carbon source type and concentration. The dynamics of BC production for the three different carbon sources evaluated at $2 \% w / v$ during 15 days is shown in Figure 2.

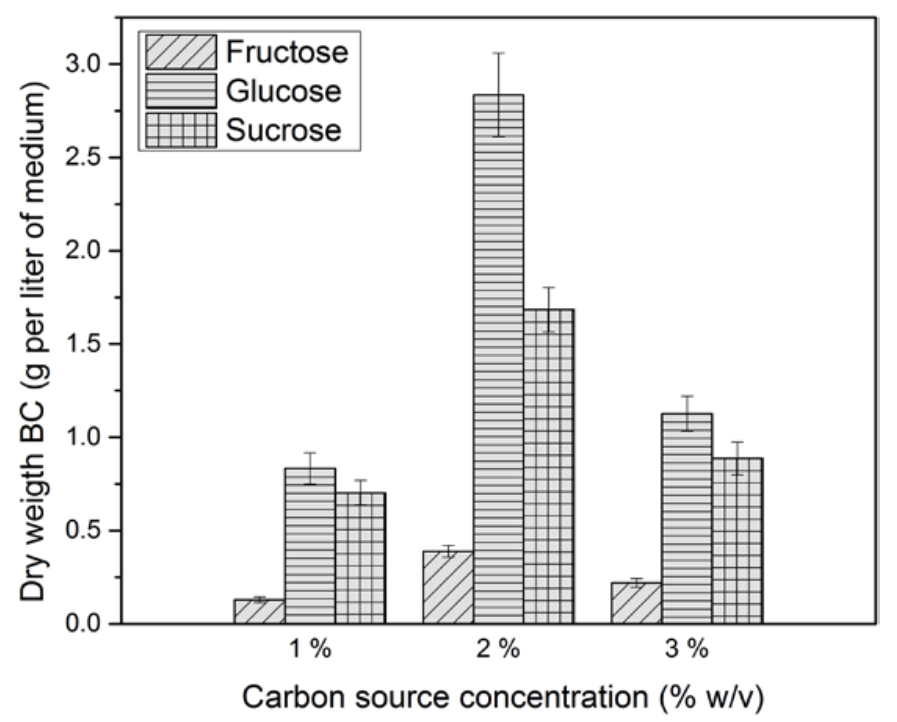

Figure 1. Bacterial cellulose yield in each carbon source culture medium at 1, 2,3\% $w / v$ at the eighth day of fermentation.

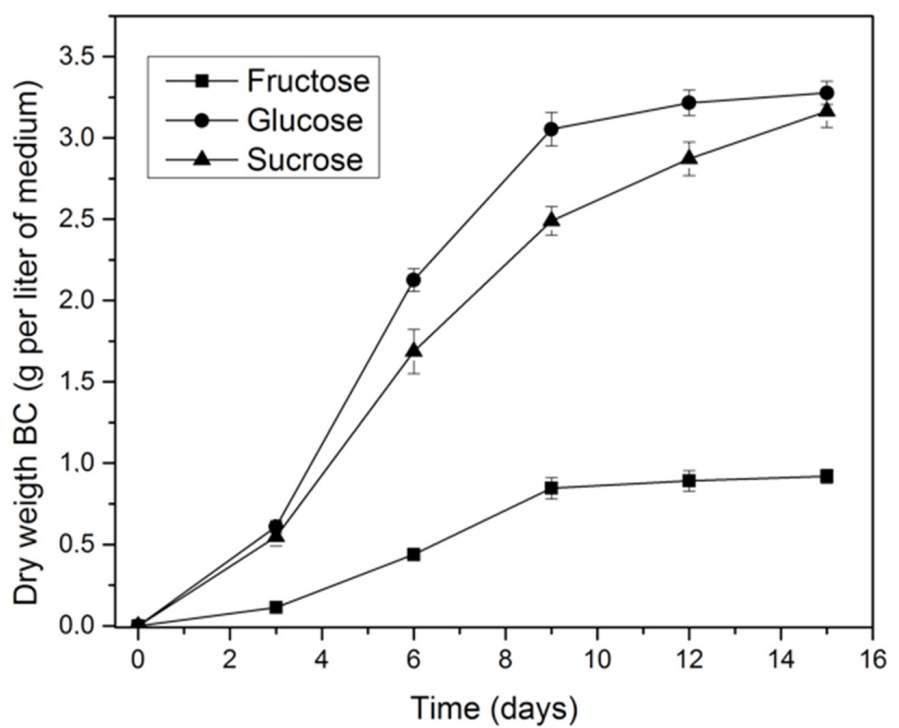

Figure 2. Bacterial cellulose produced by K. medellinesis in each culture medium with a substrate of $2 \%$.

For K. medellinensis, the highest yield of cellulose production $(3.3 \mathrm{~g} / \mathrm{L})$ after 15 days was obtained in the glucose culture medium used as a carbon source, which has been observed and analyzed by [25], [34] for G. xylinus [16]. These researchers reported that glucose acted not only as an energy source, but also as a perfect precursor for cellulose polymerization; consequently, glucose is commonly used as a source for cellulose production by strains of this genus.

In order to evaluate the consumption rate for each carbon source at $2 \% w / v$, the carbon source concentration was measured during fermentation for 15 days, as shown in Figure $3 a$. The product-substrate yield $\left(\mathrm{Y}_{\mathrm{PS}}\right)$ during the same time was calculated and the results are shown in Table 1. In the sucrose medium, the glucose and fructose content was also determined in order to measure the actual carbon source consumption (Figure $3 b$ ), this is because sucrose is a dimer comprised of glucose and fructose and it is expected that microorganisms break sucrose to metabolize it. 


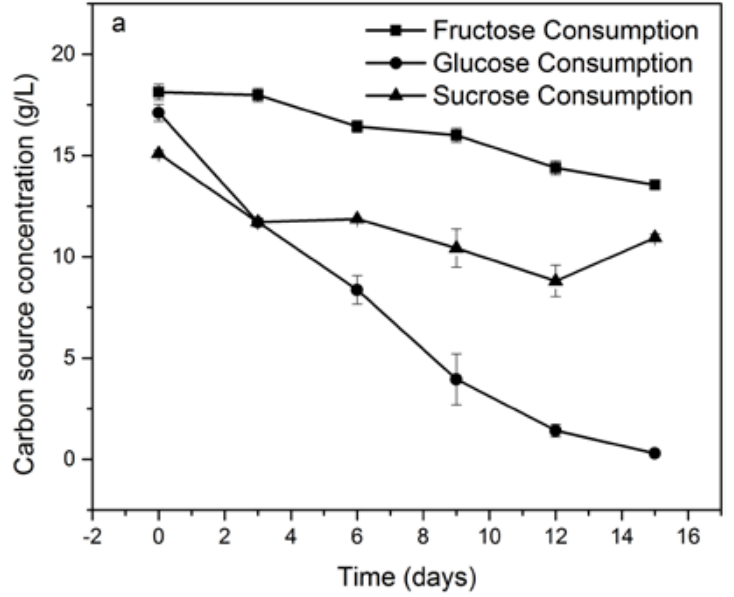

(a)

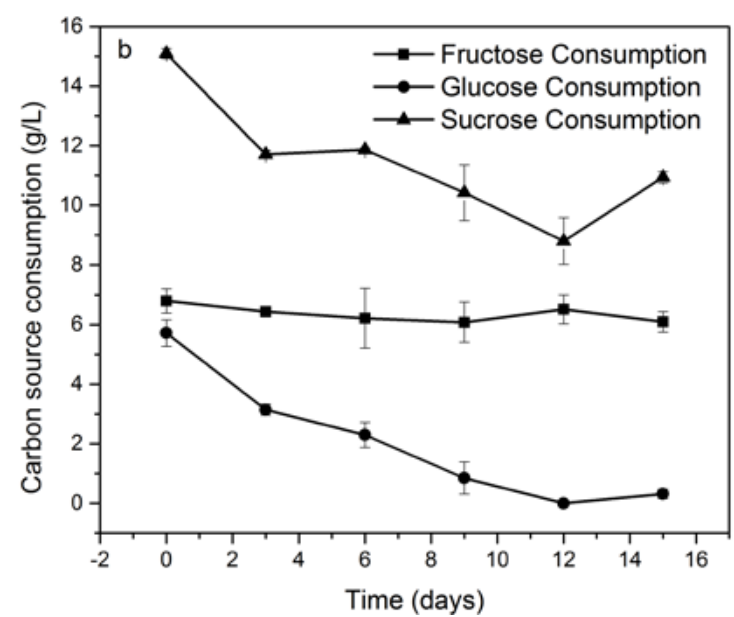

(b)

Figure 3. The dynamics of carbon source consumption: Panel (a) shows the dynamics of consumption for glucose, fructose and sucrose, each as whole and unique carbon source; panel (b) shows a magnified view of the dynamics of consumption of sucrose and its monomeric components, glucose, and fructose. Note that only glucose is consumed after sucrose hydrolysis and the fructose concentration remains the same.

Table 1. Product-substrate yield $\left(\mathrm{Y}_{\mathrm{PS}}\right)$ for each culture medium evaluated. $\mathrm{Y}_{\mathrm{PS}}$ was calculated as the ratio of dry cellulose produced and substrate consumed during fermentation.

\begin{tabular}{cc}
\hline Carbon Source & Product-Substrate Yield (g/g) \\
\hline Fructose & 0.20 \\
Glucose & 0.19 \\
Sucrose & 0.59 \\
\hline
\end{tabular}

\subsection{Effect of Carbon Source on K. medellinensis Growth}

The effect on microorganism growth of glucose, fructose, and sucrose $(2 \% w / v)$ used as a carbon source in the culture media is shown in Figure 4. For glucose and fructose, the microorganism began to grow without a clear lag phase, indicating that the microorganism did not require a phase adjustment for replication in these carbon sources. In contrast, the sucrose medium displayed a lag phase of $25 \mathrm{~h}$. Therefore, the affinity by K. medellinesis for glucose is greater than that for fructose and sucrose.

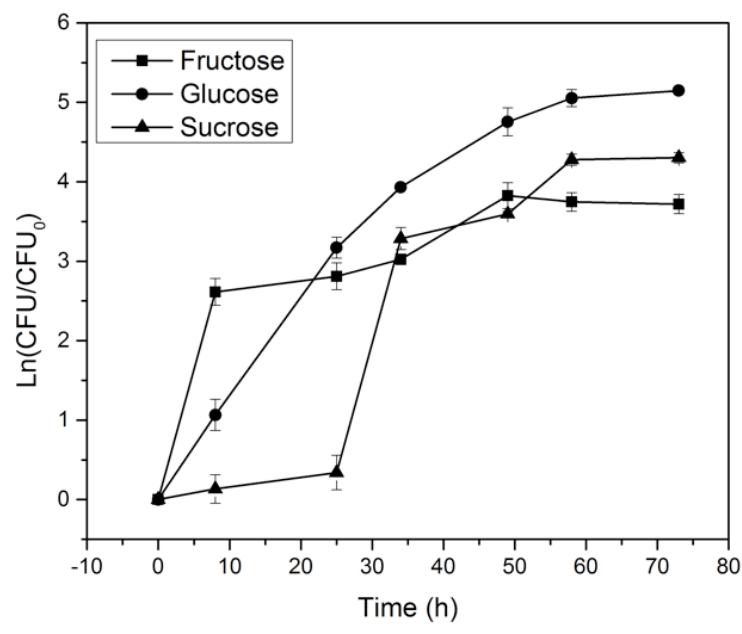

Figure 4. Growth curve of K. medellinensis with glucose, fructose and sucrose at $2 \% w / v$. 


\subsection{BC Film Characterization}

\subsubsection{Scanning Electronic Microscopy (SEM)}

The morphology characteristics of BC membranes produced by K. medellinensis from the different culture media was evaluated by scanning electronic microscopy (SEM), Figure 5. In all cases the membranes comprised a network of nanoribbons; however, differences in porosity were observed. In Figure 5a a less dense network of nanoribbons is observed from glucose, compared to the cases of fructose and sucrose, Figure $5 b, c$, respectively. The porosity was determined from the SEM images by using ImageJ software (NIMH, Bethesda, MD, USA) and the results are shown in Table 2. BC membrane from fructose showed to be lesser porous than other membranes from glucose and sucrose.

(a)

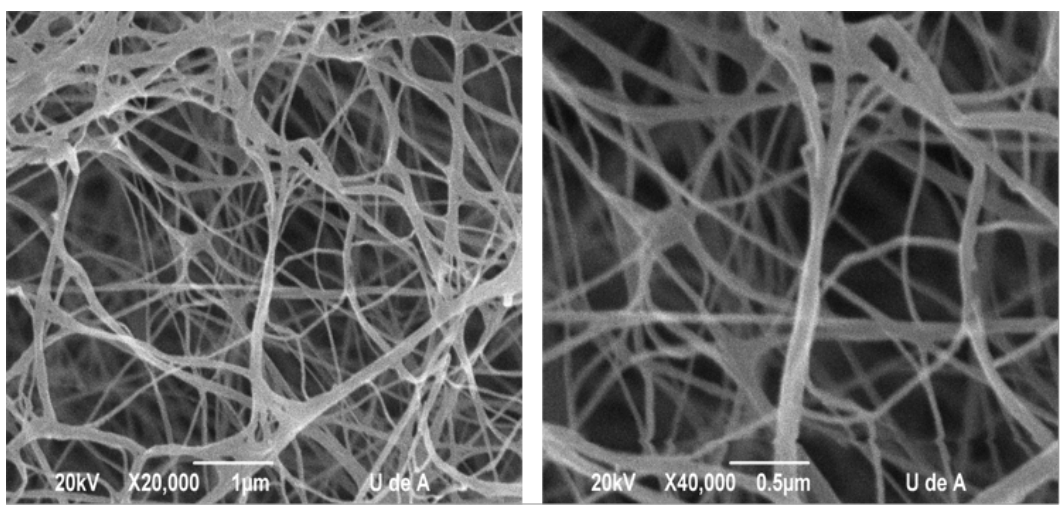

(b)
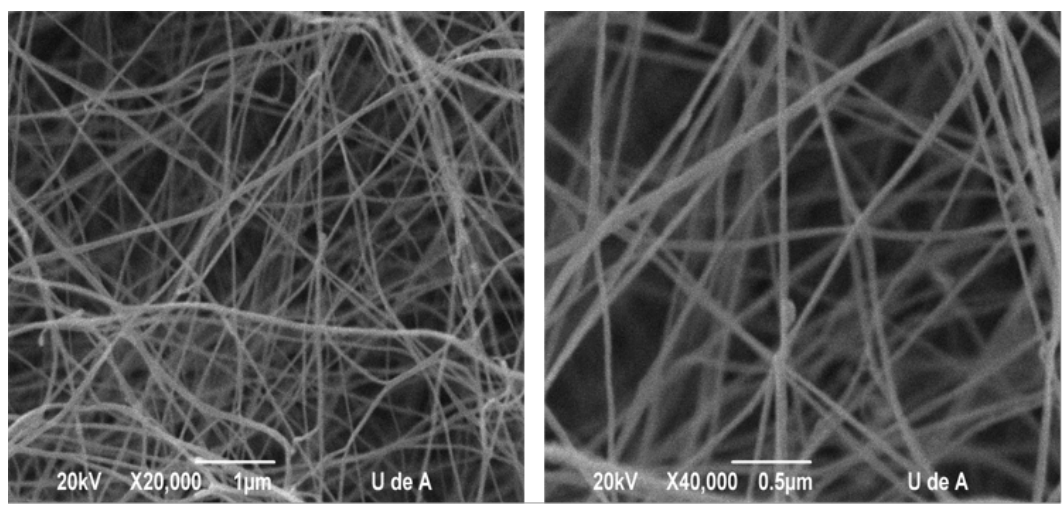

(c)
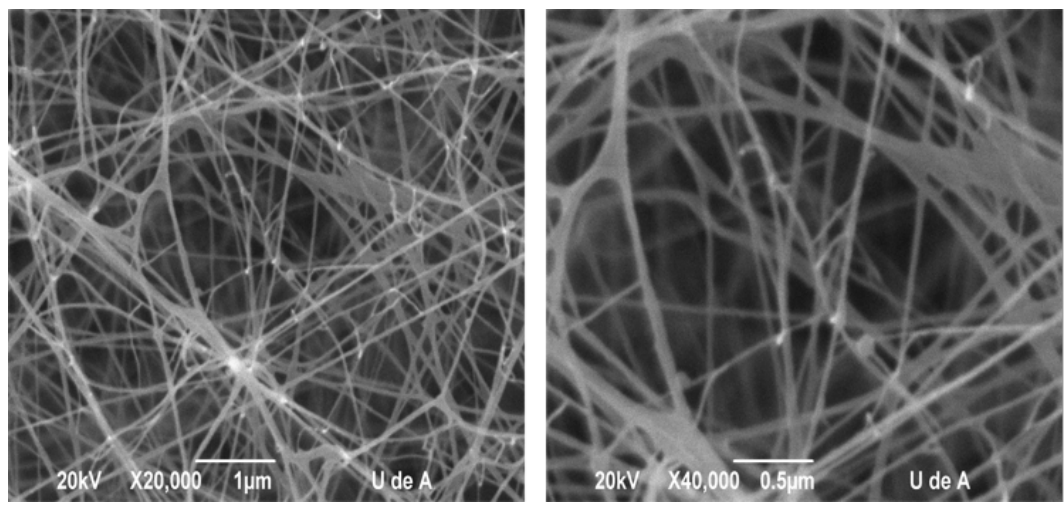

Figure 5. SEM micrograph of bacterial cellulose network obtained from different media: (a) Fructose; (b) Glucose; and (c) Sucrose. The left panel shows the 3D cellulose network at 20,000 $\times$ and the right panel shows the 3D cellulose network at $40,000 \times$. 
Table 2. Porosity of BC produced from different culture media.

\begin{tabular}{cc}
\hline Carbon Source & Porosity (\%) \\
\hline Fructose & $45.23( \pm 1.92)$ \\
Glucose & $60.07( \pm 0.55)$ \\
Sucrose & $54.70( \pm 1.47)$ \\
\hline
\end{tabular}

\subsubsection{Attenuated Total Reflection Fourier Transformed Infrared Spectroscopy (ATR-FTIR)}

The FTIR spectra of cellulose samples prepared from different media are shown in Figure 6a. The spectra exhibited the same vibration bands, indicating that BC produced from the three different media had the same chemical structure. All of the spectra revealed the characteristic bands of the cellulose I crystal structure by the existence of vibrations at $1057 \mathrm{~cm}^{-1}$ and $1427 \mathrm{~cm}^{-1}$ assigned to $\mathrm{C}-\mathrm{O}$ stretching and $\mathrm{CH}_{2}$ bending, respectively, as well as the $895 \mathrm{~cm}^{-1}$ band assigned to $\beta$-linkage of cellulose [35,36]. Other characteristics bands for $\mathrm{I}_{\alpha}$ and $\mathrm{I}_{\beta}$ allomorphs are shown in Figure 6b,c; these bands are 3240 and $750 \mathrm{~cm}^{-1}$ for the $\mathrm{I}_{\alpha}$ allomorph and 3270 and $710 \mathrm{~cm}^{-1}$ for the $\mathrm{I}_{\beta}$ allomorph, demonstrating the capacity of $K$. medellinensis to produce both allomorphs at the same time. The $\mathrm{I}_{\alpha}$ and $\mathrm{I}_{\beta}$ fractions in the $\mathrm{BC}$ produced from three media were determined by the Fourier deconvolution with OMNIC software of 710 and $750 \mathrm{~cm}^{-1}$ bands, and the results are shown in Table 3 . The $\mathrm{I}_{\alpha}$ fraction of $\mathrm{BC}$ produced was similar for all substrates and higher compared to the $\mathrm{I}_{\beta}$ fraction, indicating that the carbon source had no effect on the crystal conformation. The predominance of the I $\alpha$ allomorph is in agreement to other findings for bacterial cellulose [37].

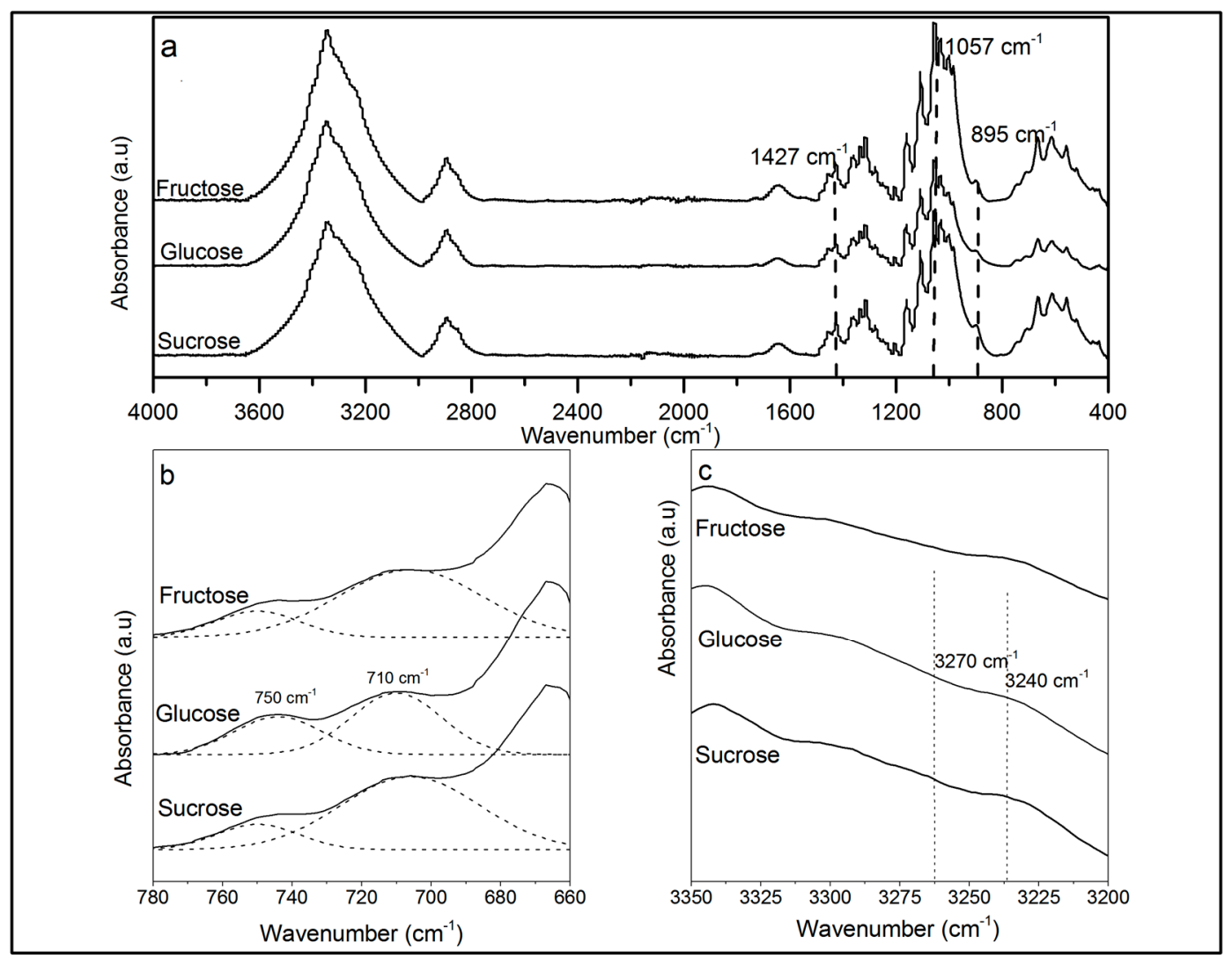

Figure 6. ATR-FT-IR spectra of bacterial cellulose produced in each media: (a) complete spectra; (b) characteristic bands at $710 \mathrm{~cm}^{-1}$ and $750 \mathrm{~cm}^{-1}$; and (c) characteristics band at $3240 \mathrm{~cm}^{-1}$ and $3270 \mathrm{~cm}^{-1}$. Straight line: fragment original spectra; dotted line: deconvolution. 
Table 3. $\mathrm{I}_{\alpha}$ fraction estimation in each BC produced from the evaluated culture media.

\begin{tabular}{cc}
\hline Substrate & Allomorph $\mathbf{I}_{\boldsymbol{\alpha}}$ Fraction Estimation $\left(\mathbf{A}_{\mathbf{7 5 0}} / \mathbf{A}_{\mathbf{7 1 0}}\right)$ \\
\hline Fructose & $0.70( \pm 0.02)$ \\
Glucose & $0.74( \pm 0.05)$ \\
Sucrose & $0.71( \pm 0.00)$ \\
\hline
\end{tabular}

\subsubsection{X-ray Diffraction}

The crystalline characteristics of BC produced with the three different media were evaluated using XRD patterns, Figure 7. For the three BC membranes, three resolved peaks assigned to 100, 010, and 110 crystallographic planes were apparent, corresponding to diffraction angles of $14.4^{\circ}, 16.7^{\circ}$, and $22.7^{\circ}$, respectively, and indexed according to the cellulose I $\alpha$ indexation described by Sugiyama, et al. [37]. The peaks were deconvoluted using the Voight peak function to calculate the crystallinity index, the interplanar crystal distance (d-spacing) and apparent crystallite size (ACS), Table 4.

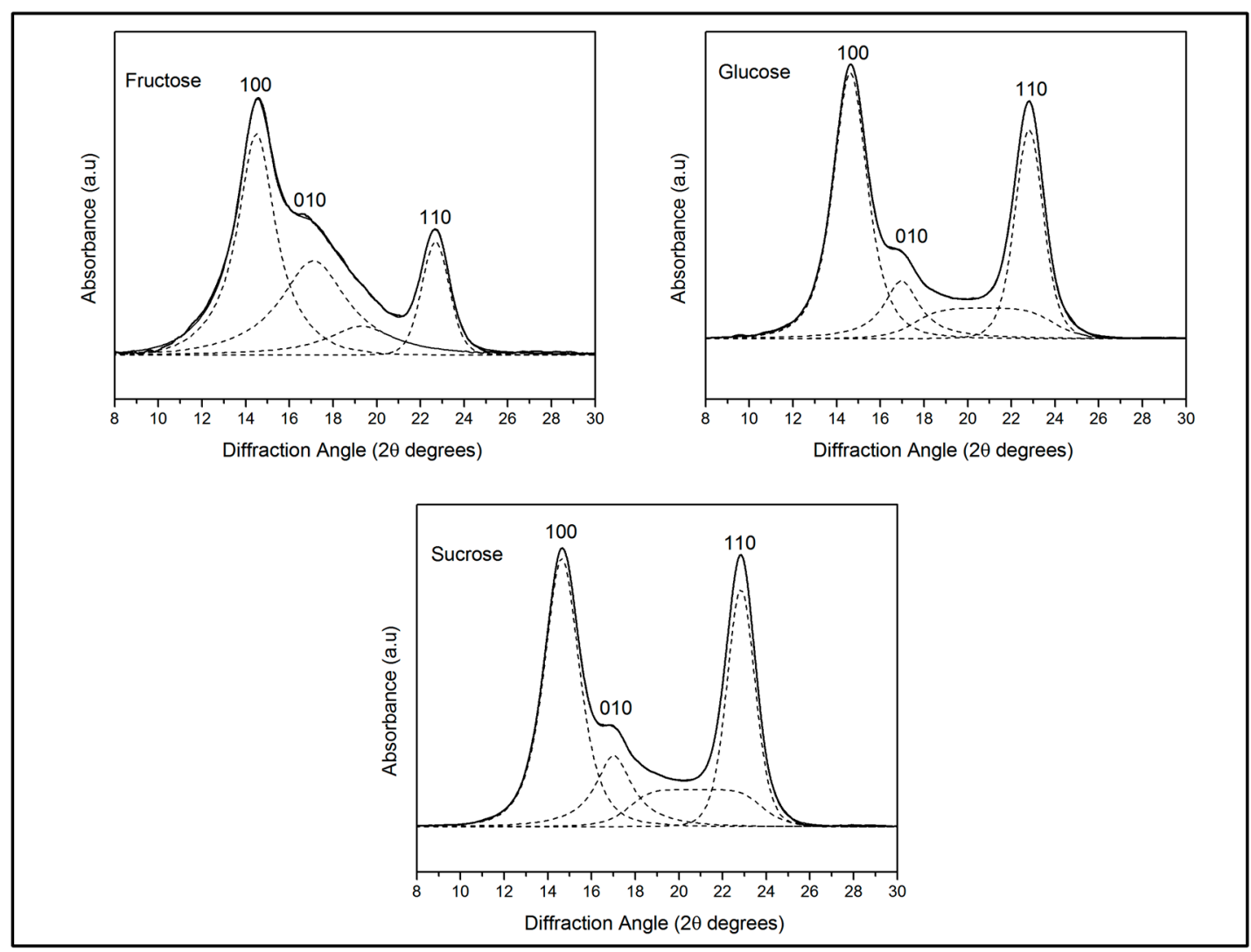

Figure 7. XDR patterns of bacterial cellulose produced from different substrate: (a) glucose; (b) fructose; and (c) sucrose.

Table 4. D-spacing, ACS, and crystallinity index in different media.

\begin{tabular}{cccccccc}
\hline Substrate & $\mathbf{1 0 0}$ & \multicolumn{2}{c}{$\mathbf{0 1 0}$} & \multicolumn{1}{c}{$\mathbf{1 1 0}$} & CI \\
\hline & $\begin{array}{c}\text { D-Spacing } \\
\mathbf{( n m )}\end{array}$ & $\begin{array}{c}\text { ACS } \\
\mathbf{( n m )}\end{array}$ & $\begin{array}{c}\text { D-Spacing } \\
\mathbf{( n m )}\end{array}$ & $\begin{array}{c}\text { ACS } \\
\mathbf{( n m )}\end{array}$ & $\begin{array}{c}\text { D-Spacing } \\
\mathbf{( n m )}\end{array}$ & $\begin{array}{c}\text { ACS } \\
\mathbf{( n m )}\end{array}$ & \\
\hline Fructose & 0.60 & 8.83 & 0.51 & 8.07 & 0.39 & 10.66 & $0.90( \pm 0.02)$ \\
Glucose & 0.60 & 8.66 & 0.52 & 8.33 & 0.39 & 10.52 & $0.83( \pm 0.03)$ \\
Sucrose & 0.60 & 8.43 & 0.52 & 8.05 & 0.38 & 10.65 & $0.85( \pm 0.06)$ \\
\hline
\end{tabular}




\section{Discussion}

Although glucose and fructose have similar chemical structures and the microorganism uses the same metabolic pathway to produce cellulose from these sources, compared to fructose $(2 \% w / v)$ the yield with glucose was nearly $86 \%$ higher. This highlights a clear substrate inhibition by fructose. A possible explanation for this observation is that the microorganism must use an isomerase to convert fructose into glucose before the polymerization begins; therefore, the microorganism requires greater energy due to enzyme synthesis, yielding a lower BC production, as suggested by other authors [8,38-40]. Another possible explanation is that the microorganism grows initially on glucose (HS medium) before its uses in a culture medium with fructose, which provoked a negative effect on enzymatic activity of fructokinase (FK) and so the possibility to phosphorylate the fructose to incorporate it into the metabolism, as was demonstrated by [41] for G. xilynus [16].

In Figure 2 it was observed that the BC production started at the third day in all culture media; however, the weight of the membranes obtained in glucose was higher compared to those obtained using fructose and sucrose for the first nine fermentation days. After this time, the mass of the membranes produced in glucose was almost constant, while that for sucrose maintained an increasing trend.

This behavior could be explained by the possibility that fructose remained in the culture medium with sucrose as carbon source. It is probable that fructose produced by sucrose hydrolysis acted as an osmotic stressor since its concentration did not vary during the 15 days of fermentation as is shown in Figure 3. The presence of solutes that cannot diffuse across the cell membrane (i.e., sugars) could trigger defense mechanisms against osmotic stress [42] and one of them is exopolysaccharide (EPS) production to protect itself. This effect was observed by Seesuriyachan et al. for other exopolysaccharides [43]. Therefore, in the medium with sucrose, the lower concentration of glucose, compared to the medium that contained glucose as the sole carbon source, instead of producing biomass, a larger part of glucose was used to produce BC, as shown in Table 1 .

Furthermore, in Figure 1 it is observed that the cellulose yield was higher in glucose than sucrose. According to some authors, this is because the microorganism needs to hydrolyze the sucrose into glucose and fructose to incorporate the glucose into its metabolism [18], but owing to the fact that the complete genome of K. medellinensis is sequenced [44] and, thus, the metabolic pathways known, the sucrose hydrolysis by this strain was not possible [45]. Therefore, the sucrose hydrolysis was caused by acid hydrolysis due to citric acid being added to the medium and the high temperature during the sterilization process, as can be confirmed in Figure 3.

The less porous $\mathrm{BC}$ membrane obtained from the fructose medium than the other two culture media could be related to larger nanoribbon network density from the fructose medium compared to glucose and sucrose media because of the branching rate of the nanoribbon network [46]. In contrast, the $\mathrm{BC}$ network from glucose showed the highest porosity and, in turn, a lower visual density of the nanoribbon network in Figure 5 follow by sucrose.

The crystallinity parameters ACS and d-spacing remained unchanged in $\mathrm{BC}$ membranes produced from the three different media. The detailed composition of the culture media did not induce differences in the crystallization process of cellulose. However, the abundance of crystallites relative to amorphous zones, determined by the crystallinity index $(\mathrm{CI})$, was slightly higher for $\mathrm{BC}$ from fructose compared to glucose and sucrose, which could be related with the length of cellulose chains that constitute the BC ribbons. Probably, ribbons synthesized in fructose were longer than those in the other films obtained from the glucose and sucrose [47] and, therefore, less porous structures resulted, as is shown in Figure 5.

\section{Materials and Methods}

\subsection{Culture Media and Growth Conditions}

The Komagataeibacter medellinensis [17] Yamada (2014) [4] strain used was isolated from homemade vinegar purchased from a local wholesale marketplace. The effect of glucose, fructose, and sucrose 
as the major carbon sources in cellulose production [32] and its dynamics of growth was evaluated through three different culture media prepared by modifying of standard Hestrin-Schramm medium: carbon source, $2 \% w / v$; yeast extract, $0.5 \% w / v$; peptone, $0.5 \% w / v ; \mathrm{Na}_{2} \mathrm{HPO}_{4}, 0.267 \% w / v$ and citric acid, until $\mathrm{pH}$ 3.6. The fermentations were performed in liquid culture media under static conditions using vessels with $48 \mathrm{~cm}^{2}$ in area and $60 \mathrm{~cm}^{3}$ in volume. The culture media were prepared at 1,2 , and $3 \% w / v$ of glucose, fructose, and sucrose (purchased from Honeywell, Merck, and Panreac, respectively), sterilized and inoculated at 10\% $v / v$ in order to determine the more adequate carbon source concentration to produce $\mathrm{BC}$ at eight days, following the proposed parameters by Castro et al. [32]. The response variable for this analysis was the amount of cellulose produced $(\mathrm{g} / \mathrm{L})$ and $\mathrm{BC}$ produced in the medium with the more adequate carbon source concentration was selected to be characterized. The experiments were performed in triplicate.

\subsection{Biomass Quantification}

Microorganism biomass was measured by optical density, and $3 \mathrm{~mL}$ of the samples were taken every $10 \mathrm{~h}, 3.3 \% v / v$ cellulase (Celuclast-Novozymes) was added to the sample and incubated at $50{ }^{\circ} \mathrm{C}$ in a water bath for two hours to degrade the cellulose and take readings of absorbance at $600 \mathrm{~nm}$ [48]. This procedure was repeated every $10 \mathrm{~h}$ to a total time of $100 \mathrm{~h}$ to use these data to building the curves for growth of K. medellinensis in each culture media.

\subsection{Consumption Dynamics of Carbon Sources}

The analysis of carbon source consumption was performed using a HPLC. Before the measurement, culture media samples were filtered through a polyethersulfone (PES) filter of $0.450 \mu \mathrm{m}$. Samples were injected onto ION exclusion column of $300 \mathrm{~mm} \times 7.800 \mathrm{~mm}$ with a solution of sulfuric acid $(0.005 \mathrm{~N})$ at a flow rate of $0.600 \mathrm{~mL} / \mathrm{min}$ at $30^{\circ} \mathrm{C}$. For nitrogen source consumption quantification, the Biuret colorimetric test was used, for which $1 \mathrm{~L}$ of standard Biuret solution and $10 \mathrm{~mL}$ of the standard solution BSA was prepared.

\subsection{Bacterial Cellulose Characterization}

The extracted membranes after 15 days of fermentation were washed with $\mathrm{KOH} 5 \%(w / v)$ aqueous solution during $14 \mathrm{~h}$ at $28{ }^{\circ} \mathrm{C}$ to remove medium components and bacteria attached, then washed with water to neutral $\mathrm{pH}$.

\subsection{Scanning Electronic Microscopy (SEM)}

SEM was used to observe the nanoribbon network morphology and its distribution in the membrane. The membranes were cut, freeze-dried, and coated with gold/palladium using an ion sputter coater. Samples were observed with a Jeol JSM 5910 LV microscope (Jeol, Tokyo, Japan) operated at $20 \mathrm{kV}$ and the images were analyzed by Image-J software for BC porosity determination.

\subsection{Attenuated Total Reflection Fourier Transformed Infrared Spectroscopy}

Before the measurement, the cellulose membranes were dried for $2 \mathrm{~h}$ at $100{ }^{\circ} \mathrm{C}$ to remove moisture. ATR-FT-IR spectra were recorded on a Nicolet 6700 spectrophotometer (Thermo Scientific, Waltham, MA, USA) in the 4000-400 $\mathrm{cm}^{-1}$ range ATR with a diamond crystal. The spectra were recorded with a resolution of $4 \mathrm{~cm}^{-1}$ and an accumulation of 256 scans.

The ratio of cellulose $I_{\alpha}$ and $I_{\beta}$ was measured according to Imai and Sugiyama, using the integrated intensities of the two-absorbance $710 \mathrm{~cm}^{-1}$ and $750 \mathrm{~cm}^{-1}$ peaks trough the relationship described in Equation (1):

$$
\mathrm{f}_{\alpha}=\frac{\mathrm{A}_{750}}{\mathrm{~A}_{750}+\mathrm{kA}_{710}}
$$


where $A_{750}$ is the absorbance of $750 \mathrm{~cm}^{-1}$ band, $A_{710}$ is the absorbance of $710 \mathrm{~cm}^{-1}$ band, and $k$ is the ratio of adsorption coefficients between those bands [48].

\subsection{X-ray Diffraction}

Dried cellulose membranes with different thicknesses were analyzed by $\mathrm{X}$-ray diffraction on a Bruker model D8 Advance (Bruker, Billerica, MA, USA) with DaVince geometry equipment operating at the Ni-filtered $\mathrm{CuK} \alpha_{1}$ radiation wavelength $(\lambda=0.15406 \mathrm{~nm})$, generated at a voltage of $45 \mathrm{kV}$ and a filament emission of $40 \mathrm{~mA}$. Data were collected in reflection mode in the 10-30 $2 \theta$-range with a step of $0.013^{\circ}$. The scans proceeded at $56.58 \mathrm{~s}$ per step. The d-spacings between the crystal planes were determined using Bragg's law expressed by Equation (2):

$$
\mathrm{d}=\frac{\lambda}{2 \sin \theta}
$$

where $\theta$ is the angle between the plane and the diffracted or incident beam and $\lambda$ is the wavelength of the X-rays. An apparent crystal size $(A C S)$ approximation was calculated using Scherrer's formula (Equation (3)):

$$
\mathrm{ACS}=\frac{0.9 \lambda}{\mathrm{FWHM} \cos \theta}
$$

where FWHM is the width of the peak at half the maximum height, $\theta$ is Bragg's angle, and $\lambda$ is the wavelength of the X-rays.

Crystallinity index (CI) was calculated according to second method described by Park et al., as the ratio of the area of all crystalline peaks to the total area.

\section{Conclusions}

This study considers the metabolic requirements of a new microorganism, namely, $\mathrm{pH}$-resistant Komagataeibacter medellinensis. The effect of different carbon sources and their concentration in the production and structure of bacterial nanocellulose $(\mathrm{BC})$ was studied. The highest $\mathrm{BC}$ yield was found after eight days of fermentation in $2 \% w / v$ of glucose $(2.80 \mathrm{~g} / \mathrm{L})$, followed by sucrose $(1.68 \mathrm{~g} / \mathrm{L})$ and fructose $(0.38 \mathrm{~g} / \mathrm{L})$. After 15 fermentation days, the $\mathrm{BC}$ yield was the same in glucose and sucrose $(3.3 \mathrm{~g} / \mathrm{L})$. The results indicate the presence of fructose in the sucrose medium, which could trigger the exopolysaccharide (EPS) production (as cellulose) as a defense mechanism against osmotic stress. Despite this, sucrose hydrolysis was produced by the action of citric acid and temperature during the sterilization process and not by K. medellinensis, as has been suggested by other authors. The biomass production was affected by carbon source, obtaining the highest production in the glucose medium and the lowest in the fructose medium, which affected the morphological characteristics of the produced BC. In fact, a reduced BC porosity was noted in the fructose medium while a higher crystallinity index was determined. The chemical features of $\mathrm{BC}$ were not affected by the carbon source. Our results are relevant to any attempt to produce $B C$, to adjust the production conditions and to understand how $B C$ could be affected by changes in culture media (carbon source and concentration).

Acknowledgments: The authors want to thank CIDI-UPB for financial support. A special thanks is given to COLCIENCIAS for the scholarship for the doctorate studies of one of the authors through grant \#762 of 2014.

Author Contributions: Margarita Castro and Mabel Torres-Taborda conceived and designed the experiments; Margarita Castro performed the experiments; Robin Zuluaga, Cristina Castro, Carlos Molina-Ramírez, and Piedad Gañán analyzed the data; Robin Zuluaga, Catalina Gómez, Beatriz Gómez, and Orlando Rojas contributed reagents, materials, and/or analysis tools; and Marlon Osorio, Cristina Castro, Piedad Gañán, and Carlos Molina-Ramírez wrote the paper.

Conflicts of Interest: The authors declare no conflict of interest. 


\section{References}

1. Varshney, V.K.; Naithani, S. Chemical functionalization of cellulose derived from nonconventional sources. In Cellulose Fibers: Bio- and Nano-Polymer Composites; Springer: Berlin/Heidelberg, Germany, 2011; pp. 43-60.

2. Shoda, M.; Sugano, Y. Recent advances in bacterial cellulose production. Biotechnol. Bioprocess. Eng. 2005, 10, 1-8. [CrossRef]

3. Ross, P.; Mayer, R.; Benziman, M. Cellulose biosynthesis and function in bacteria. Microbiol. Rev. 1991, 55, 35-58. [PubMed]

4. Yamada, Y. Transfer of Gluconacetobacter kakiaceti, Gluconacetobacter medellinensis and Gluconacetobacter maltaceti to the genus Komagataeibacter as Komagataeibacter kakiaceti comb. nov., Komagataeibacter medellinensis comb. nov. and Komagataeibacter maltaceti comb. Int. J. Syst. Evol. Microbiol. 2014, 64, 1670-1672. [CrossRef] [PubMed]

5. Bielecki, S.; Krystynowicz, A.; Turkiewicz, M.; Kalinowska, H. Bacterial cellulose. In Biopolymers Online; Wiley-VCH Verlag GmbH \& Co. KGaA: Weinheim, Germany, 2005.

6. Budhiono, A.; Rosidi, B.; Taher, H.; Iguchi, M. Kinetic aspects of bacterial cellulose formation in nata-de-coco culture system. Carbohydr. Polym. 1999, 40, 137-143. [CrossRef]

7. Castro, C.; Zuluaga, R.; Putaux, J.L.; Caro, G.; Mondragon, I.; Gañán, P. Structural characterization of bacterial cellulose produced by Gluconacetobacter swingsii sp. from Colombian agroindustrial wastes. Carbohydr. Polym. 2011, 84, 96-102. [CrossRef]

8. El-Saied, H.; Basta, A.H.; Gobran, R.H. Research Progress in Friendly Environmental Technology for the Production of Cellulose Products (Bacterial Cellulose and Its Application). Polym. Plast. Technol. Eng. 2004, 43, 797-820. [CrossRef]

9. Jung, H.I.; Jeong, J.H.; Lee, O.M.; Park, G.T.; Kim, K.K.; Park, H.C.; Lee, S.M.; Kim, Y.G.; Son, H.J. Influence of glycerol on production and structural-physical properties of cellulose from Acetobacter sp. V6 cultured in shake flasks. Bioresour. Technol. 2010, 101, 3602-3608. [CrossRef] [PubMed]

10. Keshk, S.M.A.S.; Sameshima, K. Evaluation of different carbon sources for bacterial cellulose production. Afr. J. Biotechnol. 2005, 4, 478-482.

11. Max, B.; Salgado, J.M.; Rodríguez, N.; Cortés, S.; Converti, A.; Domínguez, J.M. Biotechnological production of citric acid. Brazilian J. Microbiol. 2010, 41, 862-875. [CrossRef] [PubMed]

12. Barja, F.; Andrés-Barrao, C.; Ortega Pérez, R.; Cabello, E.M.; Chappuis, M.-L. Physiology of Komagataeibacter spp. During Acetic Acid Fermentation. In Acetic Acid Bacteria; Springer: Tokyo, Japan, 2016; pp. 201-221.

13. Zahan, K.A.; Pa'e, N.; Muhamad, I.I. Monitoring the Effect of pH on Bacterial Cellulose Production and Acetobacter xylinum 0416 Growth in a Rotary Discs Reactor. Arab. J. Sci. Eng. 2015, 40, 1881-1885. [CrossRef]

14. Castro, C.; Zuluaga, R.; Caro, G.; Gañán, P. Proceso Para Producer Celulosa Bacateriana en Presencia de un Agente Químico de Entrecruzamiento. WO2015028968A1, 5 March 2015.

15. Castro, C.; Cleenwerck, I.; Zuluaga, R.; Caro, G.; Putaux, J.-L.; Rojas, O.J.; Gañán, P. Production of Bacterial Cellulose: Use of a New Strain of Microorganism. In Handbook of Green Materials; WORLD SCIENTIFIC: Singapore, 2014; pp. 105-122.

16. Castro, C.; Cleenwerck, I.; Trcek, J.; Zuluaga, R.; De Vos, P.; Caro, G.; Aguirre, R.; Putaux, J.L.; Ganan, P. Gluconacetobacter medellinensis sp. nov., cellulose- and non-cellulose-producing acetic acid bacteria isolated from vinegar. Int. J. Syst. Evol. Microbiol. 2013, 63, 1119-1125. [CrossRef] [PubMed]

17. El-Saied, H.; El-Diwany, A.I.; Basta, A.H.; Atwa, N.A.; El-Ghwas, D.E. Production and characterization of economical bacterial cellulose. BioResources 2008, 3, 1196-1217.

18. Nguyen, V.T.; Gidley, M.J.; Dykes, G.A. Potential of a nisin-containing bacterial cellulose film to inhibit Listeria monocytogenes on processed meats. Food Microbiol. 2008, 25, 471-478. [CrossRef] [PubMed]

19. Ramana, K.V.; Tomar, A.; Singh, L. Effect of various carbon and nitrogen sources on cellulose synthesis by Acetobacter xylinum. World J. Microbiol. Biotechnol. 2000, 16, 245-248. [CrossRef]

20. Saichana, N.; Matsushita, K.; Adachi, O.; Frébort, I.; Frebortova, J. Acetic acid bacteria: A group of bacteria with versatile biotechnological applications. Biotechnol. Adv. 2015, 33, 1260-1271. [CrossRef] [PubMed]

21. Ruka, D.R.; Simon, G.P.; Dean, K.M. Altering the growth conditions of Gluconacetobacter xylinus to maximize the yield of bacterial cellulose. Carbohydr. Polym. 2012, 89, 613-622. [CrossRef] [PubMed] 
22. Hutchens, S.A.; León, R.V.; O'neill, H.M.; Evans, B.R. Statistical analysis of optimal culture conditions for Gluconacetobacter hansenii cellulose production. Lett. Appl. Microbiol. 2007, 44, 175-180. [CrossRef] [PubMed]

23. Kim, S.Y.; Kim, J.N.; Wee, Y.J.; Park, D.H.; Ryu, H.W. Production of bacterial cellulose by Gluconacetobacter sp. RKY5 isolated from persimmon vinegar. Appl. Biochem. Biotechnol. 2006, 131, 705-715. [CrossRef]

24. Masaoka, S.; Ohe, T.; Sakota, N. Production of cellulose from glucose by Acetobacter xylinum. J. Ferment. Bioeng. 1993, 75, 18-22. [CrossRef]

25. Mikkelsen, D.; Flanagan, B.M.; Dykes, G.A.; Gidley, M.J. Influence of different carbon sources on bacterial cellulose production by Gluconacetobacter xylinus strain ATCC 53524. J. Appl. Microbiol. 2009, 107, 576-583. [CrossRef] [PubMed]

26. Rani, M.; Appaiah, A. Optimization of culture conditions for bacterial cellulose production from Gluconacetobacter hansenii UAC09. Ann. Microbiol. 2011, 61, 781-787. [CrossRef]

27. Czaja, W.; Romanovicz, D.; Brown, R. Malcolm Structural investigations of microbial cellulose produced in stationary and agitated culture. Cellulose 2004, 11, 403-411. [CrossRef]

28. Chawla, P.R.; Bajaj, I.B.; Survase, S.A.; Singhal, R.S. Microbial Cellulose: Fermentative Production and Applications. Food Technol. Biotechnol. 2009, 47, 107-124.

29. Watanabe, K.; Tabuchi, M.; Morinaga, Y.; Yoshinaga, F. Structural Features and Properties of Bacterial Cellulose Produced in Agitated Culture. Cellulose 1998, 5, 187-200. [CrossRef]

30. Cheng, K.C.; Catchmark, J.M.; Demirci, A. Enhanced production of bacterial cellulose by using a biofilm reactor and its material property analysis. J. Biol. Eng. 2009, 3, 12. [CrossRef] [PubMed]

31. Castro, C.; Zuluaga, R.; Alvarez, C.; Putaux, J.L.; Caro, G.; Rojas, O.J.; Mondragon, I.; Ganan, P. Bacterial cellulose produced by a new acid-resistant strain of Gluconacetobacter genus. Carbohydr. Polym. 2012, 89, 1033-1037. [CrossRef] [PubMed]

32. Embuscado, M.E.; Marks, J.S.; BeMiller, J.N. Bacterial cellulose. II. Optimization of cellulose production by Acetobacter xylinum through response surface methodology. Food Hydrocoll. 1994, 8, 419-430. [CrossRef]

33. Klemm, D.; Schumann, D.; Udhardt, U.; Marsch, S. Bacterial synthesized cellulose-Artificial blood vessels for microsurgery. Prog. Polym. Sci. 2001, 26, 1561-1603. [CrossRef]

34. Forziati, F.H.; Rowen, J.W. Effect of changes in crystalline structure on absorption spectrum of cellulose. J. Res. Natl. Bur. Stand. 1951, 46, 38-42. [CrossRef]

35. Liang, C.Y.; Marchessault, R.H. Infrared spectra of crystalline polysaccharides. II. Native celluloses in the region from 640 to $1700 \mathrm{~cm}^{-1}$. J. Polym. Sci. 1959, 39, 269-278. [CrossRef]

36. Sugiyama, J.; Persson, J.; Chanzy, H. Combined infrared and electron diffraction study of the polymorphism of native celluloses. Macromolecules 1991, 24, 2461-2466. [CrossRef]

37. Moosavi-Nasab, M.; Yousefi, A. Biotechnological production of cellulose by Gluconacetobacter xylinus from agricultural waste. Iran. J. Biotechnol. 2011, 9, 94-101.

38. Goelzer, F.D.E.; Faria-Tischer, P.C.S.; Vitorino, J.C.; Sierakowski, M.R.; Tischer, C.A. Production and characterization of nanospheres of bacterial cellulose from Acetobacter xylinum from processed rice bark. Mater. Sci. Eng. C. 2009, 29, 546-551. [CrossRef]

39. Römling, U. Molecular biology of cellulose production in bacteria. Res. Microbiol. 2002, 153, $205-212$. [CrossRef]

40. Benziman, M.; Rivetz, B. Factors affecting hexose phosphorylation in Acetobacter xylinum. J. Bacteriol. 1972, 111, 325-333. [PubMed]

41. Csonka, L.N. Physiological and genetic responses of bacteria to osmotic stress. Microbiol. Rev. 1989, 53, 121-147. [PubMed]

42. Seesuriyachan, P.; Kuntiya, A.; Hanmoungjai, P.; Techapun, C.; Chaiyaso, T.; Leksawasdi, N. Optimization of exopolysaccharide overproduction by Lactobacillus confusus in solid state fermentation under high salinity stress. Biosci. Biotechnol. Biochem. 2012, 76, 912-917. [CrossRef] [PubMed]

43. Ogino, H.; Azuma, Y.; Hosoyama, A.; Nakazawa, H.; Matsutani, M.; Hasegawa, A.; Otsuyama, K.; Matsushita, K.; Fujita, N.; Shirai, M. Complete genome sequence of NBRC 3288, a unique cellulose-nonproducing strain of Gluconacetobacter xylinus isolated from vinegar. J. Bacteriol. 2011, 193, 6997-6998. [CrossRef] [PubMed]

44. Komagataeibacter Medellinensis. Kyoto Encyclopedia of Genomes and Genes KEGG GENOME. Available online: http:/ / www.genome.jp/kegg-bin/show_organism?menu_type=pathway_maps\&org=gxy (accessed on 20 April 2017). 
45. Gama, F.; Gatenholm, P.; Klemm, D. (Eds.) Bacterial Nanocellulose: A Sophisticated Multifunctional Material; CRC Press: Boca Raton, FL, USA, 2013.

46. Kim, U.-J.; Eom, S.H.; Wada, M. Thermal decomposition of native cellulose: Influence on crystallite size. Polym. Degrad. Stab. 2010, 95, 778-781. [CrossRef]

47. Tahara, N.; Tabuchi, M.; Watanabe, K.; Yano, H.; Morinaga, Y.; Yoshinaga, F. Degree of Polymerization of Cellulose from Acetobacter xylinum BPR2001 Decreased by Cellulase Produced by the Strain. Biosci. Biotechnol. Biochem. 1997, 61, 1862-1865. [CrossRef] [PubMed]

48. Imai, T.; Sugiyama, J. Nanodomains of $\mathrm{I}_{\alpha}$ and $\mathrm{I}_{\beta}$ Cellulose in Algal Microfibrils. Macromolecules 1998, 31, 6275-6279. [CrossRef]

(C) 2017 by the authors. Licensee MDPI, Basel, Switzerland. This article is an open access article distributed under the terms and conditions of the Creative Commons Attribution (CC BY) license (http:/ / creativecommons.org/licenses/by/4.0/). 